\title{
L-Alanine Prototrophic Suppressors Emerge from L-Alanine Auxotroph through Stress-Induced Mutagenesis in Escherichia coli
}

\author{
Harutaka Mishima ${ }^{1}$, Hirokazu Watanabe ${ }^{1}$, Kei Uchigasaki ${ }^{1}$, So Shimoda ${ }^{1}$, Shota Seki ${ }^{1}$, Toshitaka Kumagai ${ }^{2}$, \\ Tomonori Nochi $^{3}{ }^{\mathbb{D}}$, Tasuke Ando ${ }^{1}$ and Hiroshi Yoneyama ${ }^{1, *}$
}

\section{check for} updates

Citation: Mishima, H.; Watanabe, H.; Uchigasaki, K.; Shimoda, S.; Seki, S.; Kumagai, T.; Nochi, T.; Ando, T.; Yoneyama, H. L-Alanine Prototrophic Suppressors Emerge from L-Alanine Auxotroph through Stress-Induced Mutagenesis in Escherichia coli. Microorganisms 2021, 9, 472. https://doi.org/10.3390/ microorganisms 9030472

Academic Editor: Ines Arana

Received: 26 January 2021

Accepted: 22 February 2021

Published: 25 February 2021

Publisher's Note: MDPI stays neutral with regard to jurisdictional claims in published maps and institutional affiliations.

Copyright: (c) 2021 by the authors. Licensee MDPI, Basel, Switzerland. This article is an open access article distributed under the terms and conditions of the Creative Commons Attribution (CC BY) license (https:/ / creativecommons.org/licenses/by/ $4.0 /)$.
1 Laboratory of Animal Microbiology, Department of Microbial Biotechnology, Graduate School of Agricultural Science, Tohoku University, 468-1, Aramaki Aza Aoba, Aoba-ku, Sendai 980-8572, Japan; 3island.1024@gmail.com (H.M.); sendtohimtwo@yahoo.co.jp (H.W.); kei@uchigasaki.com (K.U.); so.shimoda.t7@dc.tohoku.ac.jp (S.S.); jjbgobfnanaz@yahoo.co.jp (S.S.); tasuke.ando.d4@tohoku.ac.jp (T.A.)

2 Fermlab Inc., 4-3-1-913, Shirakawa, Koto-ku, Tokyo 135-0021, Japan; tk@fermlab.com

3 Laboratory of Functional Morphology, Department of Animal Biology, Graduate School of Agricultural Science, Tohoku University, 468-1, Aramaki Aza Aoba, Aoba-ku, Sendai 980-8572, Japan; tomonori.nochi.a5@tohoku.ac.jp

* Correspondence: hiroshi.yoneyama.a4@tohoku.ac.jp

\begin{abstract}
In Escherichia coli, L-alanine is synthesized by three isozymes: YfbQ, YfdZ, and AvtA When an E. coli L-alanine auxotrophic isogenic mutant lacking the three isozymes was grown on L-alanine-deficient minimal agar medium, L-alanine prototrophic mutants emerged considerably more frequently than by spontaneous mutation; the emergence frequency increased over time, and, in an L-alanine-supplemented minimal medium, correlated inversely with L-alanine concentration, indicating that the mutants were derived through stress-induced mutagenesis. Whole-genome analysis of 40 independent L-alanine prototrophic mutants identified 16 and 18 clones harboring point mutation(s) in pyruvate dehydrogenase complex and phosphotransacetylase-acetate kinase pathway, which respectively produce acetyl coenzyme $\mathrm{A}$ and acetate from pyruvate. When two point mutations identified in L-alanine prototrophic mutants, in pta (D656A) and aceE (G147D), were individually introduced into the original L-alanine auxotroph, the isogenic mutants exhibited almost identical growth recovery as the respective cognate mutants. Each original- and isogenic-clone pair carrying the $p t a$ or aceE mutation showed extremely low phosphotransacetylase or pyruvate dehydrogenase activity, respectively. Lastly, extracellularly-added pyruvate, which dose-dependently supported L-alanine auxotroph growth, relieved the L-alanine starvation stress, preventing the emergence of L-alanine prototrophic mutants. Thus, L-alanine starvation-provoked stress-induced mutagenesis in the L-alanine auxotroph could lead to intracellular pyruvate increase, which eventually induces L-alanine prototrophy.
\end{abstract}

Keywords: L-alanine; starvation; stress-induced mutagenesis; auxotrophic mutant; prototrophic mutant; Escherichia coli

\section{Introduction}

Bacteria are continuously exposed to environmental stresses that restrict their growth, such as nutritional deprivation and exposure to xenobiotics, but bacteria are able to survive because of a versatile, pliable, and elaborate metabolic network provided by the evolutionary process. To overcome the harmful conditions caused by the blockage of specific metabolic pathways, one strategy employed is the use of isozymes that complement a blocked enzyme [1]. In terms of pathways leading to amino acid biosynthesis, all of these pathways, except that for L-alanine biosynthesis, were revealed in the mid-to-late twentieth century through extensive microbial genetics and biochemical studies [2,3], which showed that isozymes are involved in the generation of aromatic amino acids and aspartate 
family amino acids $[4,5]$. Recently, L-alanine has also been shown to be synthesized by three isozymes-AvtA, $\mathrm{YfbQ}$, and $\mathrm{YfdZ}$ - that use pyruvate as a substrate and catalyze aminotransferase activity [6,7].

An alternative to the use of isozymes is the complementation of damaged metabolic pathways by secondary enzyme activities, a phenomenon called "multicopy suppression" [8,9], which has been documented to occur in both catabolic pathways [10-12] and anabolic pathways [13] affected by mutations. As examples related to catabolic pathways, a cryptic $\beta$-galactosidase, Ebg, suppresses lac Z mutants [12], and fucose metabolic enzymes can be recruited for the catabolism of L-1,2-propanediol [10] and D-arabinose [11]. Conversely, in terms of the anabolic pathway, a D-alanine auxotroph produced by doubleknockout mutation of the genes alr and dadX gains the ability to synthesize D-alanine through a suppressor mutation that results in high expression of metC [13]; this finding clearly implies that the cystathionine $\beta$-lyase MetC shows promiscuous activity and generates D-alanine when expressed at a high level. Moreover, by using a shotgun-cloning experiment, we previously found that, besides D-alanine, $\operatorname{ser} C$ on a multicopy plasmid can suppress the growth defect of an Escherichia coli L-alanine auxotroph lacking the aforementioned three isozymes, but a single chromosomal copy of serC cannot [6]; our results demonstrated that SerC exhibits promiscuous activity and generates L-alanine. Furthermore, another study reported that other transaminase genes also suppress the growth defect of the L-alanine auxotroph, either efficiently ( $\arg D$ and $a s t C)$ or partially (aspC, gabT, puuE, tyrB, and ygiG) [7]. These findings indicate that bacteria can respond to nutritional stress (i.e., to starvation) in a more adaptable manner than previously recognized.

During the course of our previous study, in which the L-alanine auxotrophic mutant was isolated using a traditional microbial genetics approach, we found that L-alanine prototrophic suppressor mutants appeared at a frequency higher than that through spontaneous mutation. This unexpected phenomenon poses two fundamental questions: (1) What mutation(s) conferred the L-alanine auxotroph the prototrophic phenotype? (2) Were the suppressor mutants generated due to stress-induced mutagenesis? Here, we analyzed the genome sequence of independently isolated suppressor mutants to identify the mutations that result in the L-alanine prototrophy and the response of the L-alanine auxotroph toward various conditions that relieve L-alanine starvation.

\section{Materials and Methods}

\subsection{Bacterial Strains, Plasmids, and Culture Conditions}

The E. coli strains and plasmids used in this study are listed in Table 1. Bacterial cells were cultured at $37^{\circ} \mathrm{C}$ in Luria-Bertani (LB) medium containing $1 \%$ tryptone, $0.5 \%$ yeast extract, and $0.5 \% \mathrm{NaCl}$ (pH 7.2) or minimal medium containing $22 \mathrm{mM}$ glucose, $7.5 \mathrm{mM}$ $\left(\mathrm{NH}_{4}\right)_{2} \mathrm{SO}_{4}, 1.7 \mathrm{mM} \mathrm{MgSO}, 7 \mathrm{mM} \mathrm{K} \mathrm{SO}_{4}, 22 \mathrm{mM} \mathrm{NaCl}$, and $100 \mathrm{mM}$ sodium phosphate (pH 7.1) [14]. When necessary, kanamycin (KM, $6.25 \mu \mathrm{g} / \mathrm{mL})$, gentamicin (GM, $6.25 \mu \mathrm{g} / \mathrm{mL})$, and chloramphenicol $(\mathrm{CP}, 25 \mu \mathrm{g} / \mathrm{mL}$ ) were added to the medium. Growth was monitored by measuring the absorbance at $660 \mathrm{~nm}\left(\mathrm{~A}_{660}\right)$. 
Table 1. Strains and plasmids used in this study.

\begin{tabular}{|c|c|c|}
\hline Strain or Plasmid & Relevant Properties & Source \\
\hline \multicolumn{3}{|l|}{ Strain } \\
\hline Escherichia coli W3110 & Wild-type & Laboratory strain \\
\hline HYE032 & $\begin{array}{c}\text { avt } A:: \mathrm{GM}, \text { yfbQ::KM, yfdZ::FRT, L-alanine } \\
\text { auxotroph }\end{array}$ & [6] \\
\hline JM109 & 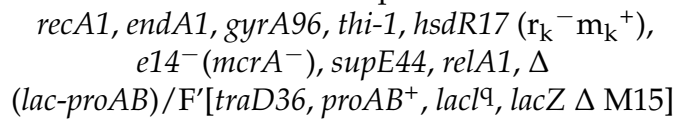 & Laboratory strain \\
\hline \#8-2M & $\begin{array}{l}\text { Isogenic mutant of HYE032 with a } \\
\text { point-mutation found in a suppressor mutant } \\
\# 8-2 \text { in pta gene }\end{array}$ & This study \\
\hline$\# 13-1 \mathrm{M}$ & $\begin{array}{c}\text { Isogenic mutant of HYE032 with a } \\
\text { point-mutation found in a suppressor mutant } \\
\# 13-1 \text { in aceE gene }\end{array}$ & This study \\
\hline$\# 3$ to \#70 * & $\begin{array}{l}\text { L-alanine prototrophic derivatives isolated from } \\
\text { HYE032 }\end{array}$ & This study \\
\hline $\begin{array}{l}\text { Plasmid } \\
\text { pTH18cs1 }\end{array}$ & \multirow{2}{*}{$\begin{array}{c}\text { cat1, lacZ', rep } A_{t s 1} \text {, derivative of pSC101 } \\
\text { pTH18cs1 harboring } 0.5-\mathrm{kb} \text { PCR fragment of } p t a \\
\text { gene }\end{array}$} & [15] \\
\hline pTH8-2 & & This study \\
\hline pTH13-1 & $\begin{array}{l}\text { pTH18cs1 harboring 1.8-kb PCR fragment of } \\
\text { aceE gene }\end{array}$ & This study \\
\hline
\end{tabular}

\subsection{Isolation of L-Alanine Prototrophic Clones}

E. coli L-alanine auxotrophic strain HYE032 cells $\left(10^{6}-10^{9}\right)$ were placed on minimal agar medium containing $6.25 \mu \mathrm{g} / \mathrm{mL} \mathrm{KM}$ and $6.25 \mu \mathrm{g} / \mathrm{mL} \mathrm{GM}$ and grown at $37{ }^{\circ} \mathrm{C}$. At 2,3, or 4 days after incubation, newly appeared colonies were purified in LB agar medium containing $6.25 \mu \mathrm{g} / \mathrm{mL} \mathrm{KM}$ and $6.25 \mu \mathrm{g} / \mathrm{mL} \mathrm{GM}$, and the phenotypes of the resulting clones were determined on minimal agar medium supplemented with or without $20 \mu \mathrm{g} / \mathrm{mL}$ L-alanine.

\subsection{Frequencies of Mutants Grown in Minimal Medium with or without L-Alanine Supplementation}

E. coli HYE032 was grown overnight in an LB medium containing $6.25 \mu \mathrm{g} / \mathrm{mL} \mathrm{KM}$ and $6.25 \mu \mathrm{g} / \mathrm{mL} \mathrm{GM}$, and the cells were collected through centrifugation $\left(15,000 \times g, 23{ }^{\circ} \mathrm{C}\right.$, $5 \mathrm{~min}$ ), washed thrice with $0.85 \% \mathrm{NaCl}$, and resuspended in the original volume of the same solution. We inoculated the resulting cells $(5 \mu \mathrm{L})$ into a minimal liquid medium $(5 \mathrm{~mL})$ containing $6.25 \mu \mathrm{g} / \mathrm{mL} \mathrm{KM}, 6.25 \mu \mathrm{g} / \mathrm{mL} \mathrm{GM}$, and L-alanine $(100,50,10,1$, or $0.1 \mu \mathrm{g} / \mathrm{mL})$ and cultured the cells until the late-log phase, and then counted the cells that grew on minimal agar medium containing $6.25 \mu \mathrm{g} / \mathrm{mL} \mathrm{KM}$ and $6.25 \mu \mathrm{g} / \mathrm{mL} \mathrm{GM}$ after incubation for 2 days at $37^{\circ} \mathrm{C}$. The frequencies of the mutants that appeared on minimal agar medium were calculated by normalizing against the total cell count obtained with LB agar medium containing $6.25 \mu \mathrm{g} / \mathrm{mL} \mathrm{KM}$ and $6.25 \mu \mathrm{g} / \mathrm{mL}$ GM.

\subsection{DNA Sequencing and Annotation of Mutations}

Chromosomal DNA of L-alanine suppressor mutants was extracted using phenol and chloroform-isoamyl alcohol (24:1), as described [16], and after shearing the isolated DNA, a fragment library was prepared using a bar-coding protocol, according to the manufacturer's instructions (Thermo Fisher Scientific, Waltham, MA, USA). Subsequently, genome sequencing was performed using a SOLiD 5500XL sequencer. All sequence reads obtained were mapped to the reference genome of E. coli W3110 (Accession Number NC_007779) by using bowtie2 [17] and samtools [18]. Candidate mutations (point mutations and InDels) as differences from the reference genome sequence were identified by FreeBayes [19] and 
filtered using vcftools [20]. Lastly, all candidate mutations were verified by using the dideoxy chain-termination sequencing method [21] with the primers listed in Table S1.

\subsection{Construction of Isogenic Mutants}

To construct HYE032 isogenic mutants carrying respectively the point mutation of L-alanine prototrophic suppressors \#8-2 and \#13-1, we first amplified the DNA fragments harboring the point mutation of each suppressor clone by performing PCR with specific primers (Table 2) and the chromosomal DNA of \#8-2 and \#13-1, respectively, as the template. The resulting fragments were digested with $\mathrm{XbaI}$ and cloned into the $\mathrm{XbaI}$ site of pTH18cs1 [15], which generated pTH8-2 and pTH13-1, whose mutations were derived from \#8-2 and \#13-1, respectively. After the transformation of pTH8-2 and pTH13-1 into HYE032, the resulting transformants were grown in LB medium containing $12.5 \mu \mathrm{g} / \mathrm{mL} \mathrm{KM}, 12.5 \mu \mathrm{g} / \mathrm{mL} \mathrm{GM}$, and $25 \mu \mathrm{g} / \mathrm{mL} \mathrm{CP}$ at $42{ }^{\circ} \mathrm{C}$ overnight, and then integrants were selected on LB agar medium containing $12.5 \mu \mathrm{g} / \mathrm{mL} \mathrm{KM}, 12.5 \mu \mathrm{g} / \mathrm{mL} \mathrm{GM}$, and $25 \mu \mathrm{g} / \mathrm{mL} \mathrm{CP}$; subsequently, the isogenic mutants, \#8-2M and \#13-1M, respectively, were obtained by selecting $\mathrm{CP}$-susceptible clones.

Table 2. Primers used for the construction of isogenic mutants.

\begin{tabular}{ccc}
\hline Primer & Nucleotide Sequence $\mathbf{( 5}^{\prime} \mathbf{- 3} \mathbf{)}$ & Comment \\
\hline pta-Fwd & tgtctagaCACTACCGCAAACACCATCC & $X b a I$ tag * \\
pta-Rev & gttctagaACCAACGTATCGGGCATTGC & $X b a I$ tag * \\
aceE-Fwd & attctagaATTCGCGTCGCAATTGCTCT & $X b a I$ tag * \\
aceE-Rev & tttctagaAACGAAAGCTTCAGAGCACG & $X b a I$ tag * \\
pta-seq & GATGACGAGATTACTGCTGC & for sequencing \\
aceE-seq & AAAAGACCTCGAACTGGGC & for sequencing \\
* Lowercase letters including underlined nucleotides represent tags used for cloning.
\end{tabular}

\subsection{Crude Cell Extract Preparation}

E. coli cells were grown in LB medium containing appropriate antibiotics to the mid$\log$ phase $\left(\mathrm{A}_{660} \cong 0.6\right)$, collected through centrifugation $\left(15,000 \times \mathrm{g}, 4{ }^{\circ} \mathrm{C}, 5 \mathrm{~min}\right)$, washed thrice with ice-cold $50 \mathrm{mM}$ potassium phosphate buffer $(\mathrm{pH} 8.0)$ or $50 \mathrm{mM}$ Tris- $\mathrm{HCl}$ ( $\mathrm{pH}$ 8.0), and then resuspended in the original volume of the same solution. The collected cells were disrupted by applying 5 cycles of 15-s sonic oscillation with 45-s intermittent cooling in an ice bath by using a Bioruptor (UCD-250, CosmoBio Co., Tokyo, Japan). The supernatant obtained through centrifugation $\left(15,000 \times g, 4{ }^{\circ} \mathrm{C}, 15 \mathrm{~min}\right)$ was used for assaying enzyme activity.

\subsection{Enzyme Activity Assay}

Pyruvate dehydrogenase (PDH) activity was determined spectrophotometrically by monitoring NADH formation at $340 \mathrm{~nm}\left(\varepsilon_{340}=6220 \mathrm{~L} / \mathrm{mol} / \mathrm{cm}\right)$ at $25^{\circ} \mathrm{C}$ [22]. The reaction mixtures contained $50 \mathrm{mM}$ potassium phosphate $(\mathrm{pH} 8.0), 0.2 \mathrm{mM}$ thiamine pyrophosphate, $0.1 \mathrm{mM}$ coenzyme A, $1 \mathrm{mM} \mathrm{MgCl}, 0.3 \mathrm{mM}$ dithiothreitol, $2.5 \mathrm{mM} \mathrm{NAD}^{+}, 100 \mu \mathrm{g} / \mathrm{mL}$ bovine serum albumin, and crude cell extracts. The reaction was initiated by adding pyruvate to a final concentration of $5 \mathrm{mM}$.

Phosphotransacetylase (PTA) activity was determined spectrophotometrically by monitoring thioester bond formation at $233 \mathrm{~nm}\left(\varepsilon_{233}=5550 \mathrm{~L} / \mathrm{mol} / \mathrm{cm}\right)$ at $25^{\circ} \mathrm{C}$ [23]. The reaction mixtures contained $50 \mathrm{mM}$ Tris $-\mathrm{HCl}(\mathrm{pH} 8.0), 20 \mathrm{mM} \mathrm{KCl}, 0.2 \mathrm{mM}$ coenzyme A, $2 \mathrm{mM}$ dithiothreitol, and crude cell extracts. The reaction was initiated by adding acetyl phosphate to a final concentration of $10 \mathrm{mM}$.

\subsection{Protein Concentration Measurement}

Protein concentrations were determined by using the Lowry method with bovine serum albumin as a standard [24]. 


\subsection{Statistics}

Statistical analyses involving one-way ANOVA with the Kruskal-Wallis test (Figure 1a,b, Figure $5 \mathrm{a}, \mathrm{b}$ and Figure 6) and t-test (Figure 6) were performed using Prism version 7 (GraphPad Software, San Diego, CA, USA).

\section{Results}

\subsection{L-Alanine Prototrophs Emerge from L-Alanine Auxotroph through Suppressor Mutation}

When the L-alanine auxotroph HYE032 [6] was continuously incubated in a minimal liquid medium for $>2$ days, bacterial growth was reproducibly observed in this medium without L-alanine supplementation (Figure S1a). To characterize the precise growth behavior of the cells that grew, the clones that proliferated in the liquid medium were purified on LB agar medium and the resulting single clones were cultured in the same minimal liquid medium. All clones started to grow considerably faster than their parental strain, HYE032, and showed a growth pattern similar to that of the wild-type strain W3110 (Figure S1b). Because the L-alanine auxotroph HYE032 was constructed through homologous recombination of three genes $(y f b Q, y f d Z$, and $a v t A)$ encoding the major L-alanine synthesizing enzymes, the clones are highly unlikely to have emerged due to a back mutation in one of these genes. Thus, a suppressor mutation(s) generated the obtained clones exhibiting L-alanine prototrophy.

\subsection{L-Alanine Prototrophic Suppressor Mutants are Generated through Stress-Induced Mutagenesis}

Because the L-alanine prototrophic suppressors appeared at a frequency substantially higher than that expected for mutants generated by a spontaneous mutation, we sought to quantify the suppressors that emerged during the course of incubation (2-4 days) on minimal agar medium; the number of suppressors that appeared increased in an incubation time-dependent manner (Figure 1a), which suggested that the appearance of the suppressors was caused by mutagenesis induced by stress (here, L-alanine starvation). In this scenario, removal of the stress would be expected to prevent the appearance of the suppressor mutants, and we tested this by measuring the frequency of L-alanine prototrophic suppressors in a population of late-log-phase cells grown in a minimal liquid medium; the frequencies of appearance of the suppressor mutants were inversely related to the concentration of L-alanine added to the minimal medium (Figure 1b). These results clearly indicate that the obtained L-alanine prototrophic suppressors were generated through mutagenesis induced by stress (L-alanine starvation).

(a)

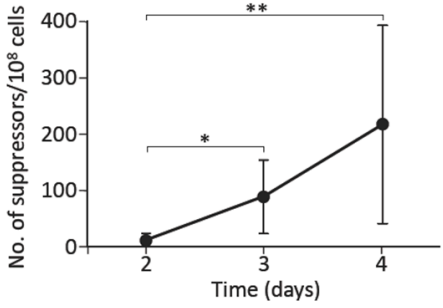

(b)

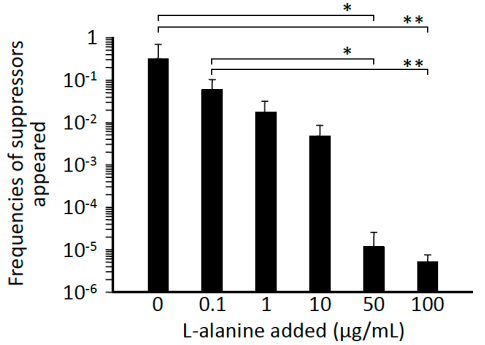

Figure 1. Effect of incubation time and L-alanine concentration on the appearance of L-alanine prototrophic suppressors. L-alanine auxotroph HYE032 cells were seeded on minimal agar medium without L-alanine supplementation and incubated at $37^{\circ} \mathrm{C}$ for $2-4$ days. (a) Colonies that newly appeared on each day were counted and the frequency of suppressors per $10^{8}$ cells inoculated was calculated. Points represent means and standard deviation from $>3$ independent experiments. (b) HYE032 cells were inoculated into a minimal liquid medium containing various concentrations of L-alanine (0.1-100 $\mu \mathrm{g} / \mathrm{mL})$ and incubated to late-log phase, and the frequency at which suppressors appeared was evaluated. Data represent means and standard deviation from 3 independent experiments. Statistical analyses; $(\mathbf{a})^{*} p<0.05,{ }^{* *} p<0.0001$ and $(\mathbf{b}){ }^{*} p<0.01,{ }^{* *} p<0.001$. 


\subsection{L-Alanine Prototrophic Suppressors Show Distinct Levels of Growth Recovery}

The L-alanine prototrophic suppressors obtained in minimal liquid medium showed an overall similar pattern of growth recovery (Figure S1b); this supported the possibility that the suppressors were derived from a single mutation event that generated the offspring from the original mutant HYE032, meaning that most of these suppressors could represent the same clone. Hence, they were supposed to show similar patterns of growth. We thus selected L-alanine prototrophic suppressors on minimal agar medium without L-alanine supplementation to obtain distinct mutants, i.e., genetically independent clones. After isolating several individual suppressor mutants, we measured their growth in a minimal liquid medium and observed varying degrees of growth recovery (Figure 2). Intriguingly, the suppressors obtained after 2,3, or 4 days of incubation showed slightly dissimilar patterns of growth recovery (Figure S2); specifically, the suppressors obtained after 4-day incubation exhibited slower growth initiation than did the clones obtained within 3 days of incubation. The results suggested that individual suppressor clones, isolated using minimal agar medium carried distinct mutation(s), which contributed to the varying degrees of growth suppression of the individual clones.

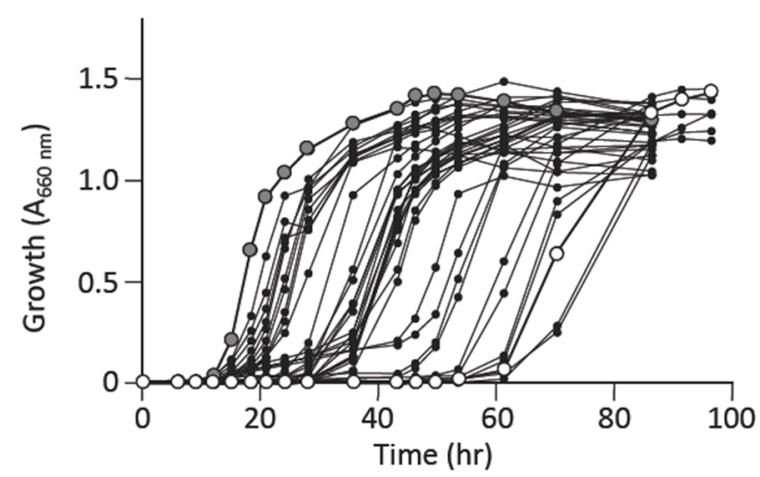

Figure 2. Growth of distinct L-alanine prototrophic suppressors that appeared on minimal agar medium. Here, 32 independent clones were grown in a minimal liquid medium without L-alanine supplementation. Symbols: large grey circles, W3110; large open circles, HYE032; small black circles, independent L-alanine suppressors. The figure shows a representative result from $>2$ experiments.

\subsection{Factors Supporting Growth of L-Alanine Auxotroph in Minimal Medium}

The aforementioned results were interpreted to imply that a suppressor mutation caused a metabolic-flow change that ultimately led to L-alanine synthesis, which was achieved by an enzyme(s) other than the three major alanine synthesizing enzymes, YfbQ, YfdZ, and AvtA [6,7]. Notably, the phenomenon of multicopy suppression was observed in the case of the L-alanine auxotroph: HYE032 cells harboring a multicopy plasmid carrying ser $\mathrm{C}$, which encodes 3-phosphoserine aminotransferase, grew on minimal medium without L-alanine supplementation [6], whereas the host HYE032 cells harboring a single copy of wild-type serC in the genome could not grow on the same medium [6]. The results suggested that highly expressed SerC could use (or recognize) pyruvate as a minor substrate, which would then result in the provision of L-alanine to support the growth of the L-alanine auxotroph. Therefore, we assessed the impact of supplementation of pyruvate, an immediate precursor ketoacid of L-alanine, and various other amino acids, including L-glutamic acid, an amino donor of alanine aminotransferases. Pyruvate supported the growth of HYE032 cells in a concentration-dependent manner (Figure 3), and L-glutamic acid also supported the growth to a certain extent (Figure S3). These results implied that conditions that cause an increase in the levels of intracellular substrates for L-alanine synthesis, particularly pyruvate, enabled the L-alanine auxotroph to grow in minimal medium. 


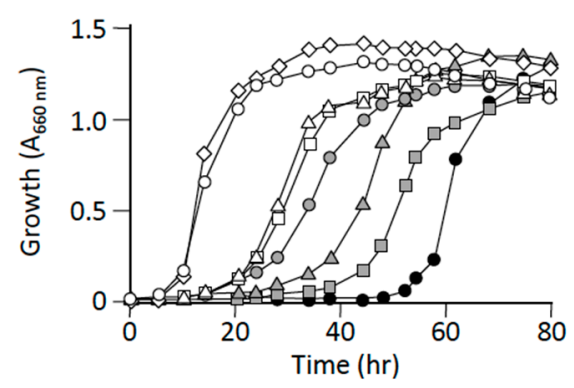

Figure 3. Effect of pyruvate on the growth of L-alanine auxotroph HYE032. HYE032 cells were inoculated into a minimal liquid medium containing various amounts of pyruvate $(10-500 \mu \mathrm{g} / \mathrm{mL})$, and growth was monitored by measuring the absorbance at $660 \mathrm{~nm}$. Symbols: open diamonds, W3110 with no supplementation; open circles, HYE032 with $100 \mu \mathrm{g} / \mathrm{mL}$ L-alanine; open triangles, HYE032 with $500 \mu \mathrm{g} / \mathrm{mL}$ pyruvate; open squares, HYE032 with $300 \mu \mathrm{g} / \mathrm{mL}$ pyruvate; grey circles, HYE032 with $100 \mu \mathrm{g} / \mathrm{mL}$ pyruvate; grey triangles, HYE032 with $20 \mu \mathrm{g} / \mathrm{mL}$ pyruvate; grey squares, HYE032 with $10 \mu \mathrm{g} / \mathrm{mL}$ pyruvate; closed circles, HYE032 with no supplementation. The figure shows representative results from $>2$ experiments.

\subsection{Identification of Suppressor Mutations that Cause L-Alanine Auxotroph to Grow without} L-Alanine Supplementation

The results described in the preceding subsection led us to infer that the suppressor mutants isolated using L-alanine-lacking minimal medium potentially carry mutations that lead to the generation of pyruvate by inducing a metabolic change. To identify the mutations that could cause this phenotypic change, we performed whole-genome sequencing of the suppressor mutants and identified point mutations in 40 individual mutants (Table 3). All ambiguous mutations detected using a SOLiD 5500XL sequencer were verified using the Sanger method [21], and we ultimately found that 30 clones carried a mutation(s) in a single gene (Table S2). Interestingly, among these clones, suppressor clone \#39-2 harbored two distinct point mutations in aceE, a missense mutation (A206V) and a silent mutation (V290). Furthermore, nine suppressor clones concurrently carried a point mutation in two genes, and one clone carried a point mutation in three genes (Table S2). The finding that multiple point mutations exist in a single clone agrees with the notion that L-alanine suppressors appeared through stress-induced mutagenesis and not spontaneous mutation. 
Table 3. Results of mutations in individual L-alanine prototrophic suppressor mutants.

\begin{tabular}{|c|c|c|c|c|}
\hline $\begin{array}{c}\text { Suppressor } \\
\text { Strain }\end{array}$ & $\begin{array}{l}\text { Days of } \\
\text { Isolation }\end{array}$ & Gene & Nucleotide Change & Amino Acid Change \\
\hline \multirow[t]{2}{*}{$\# 3$} & 2 & aceE & T110A & $\mathrm{I} 37 \mathrm{~N}$ \\
\hline & & flgJ & $\mathrm{A} 123>\mathrm{AA} * 1$ & 42 frameshift \\
\hline \#4-2 & 2 & aceE & $\mathrm{T} 110 \mathrm{~A}$ & $\mathrm{I} 37 \mathrm{~N}$ \\
\hline \#5-1 & 2 & aceE & A775G & N259D \\
\hline \#8-2 & 2 & pta & A1967C & D656A \\
\hline \multirow[t]{2}{*}{$\# 10-1$} & 2 & aceE & T110A & $\mathrm{I} 37 \mathrm{~N}$ \\
\hline & & суaA & C1957T & $\mathrm{R} 653 \mathrm{C}$ \\
\hline$\# 11-2$ & 2 & aceF & A1504C & T502P \\
\hline$\# 12-2$ & 2 & aceE & A775C & $\mathrm{N} 259 \mathrm{H}$ \\
\hline$\# 13-1$ & 2 & aceE & G440A & G147D \\
\hline \multirow[t]{3}{*}{ \#14-1 } & 2 & aceE & $\mathrm{C} 802 \mathrm{~T}$ & P268S \\
\hline & & $\operatorname{cpxP}$ & $\mathrm{T} 269 \mathrm{G}$ & F90C \\
\hline & & $y h b O$ & T5A & S2R \\
\hline \multirow[t]{2}{*}{$\# 15-1$} & 2 & $p t a$ & A1967C & D656A \\
\hline & & $g s p E$ & A1381C & K461Q \\
\hline$\# 16-2$ & 2 & pta & A1967C & D656A \\
\hline \multirow[t]{2}{*}{$\# 17-2$} & 2 & pta & A1967C & D656A \\
\hline & & plsB & G2198T & R733L \\
\hline \#18-1 & 2 & pta & A1967C & D656A \\
\hline \#19 & 2 & pta & A1967C & D656A \\
\hline \#20 & 2 & pta & G1420T & E474stop \\
\hline$\# 21$ & 2 & pta & A1967C & D656A \\
\hline \multirow[t]{2}{*}{$\# 23$} & 2 & pta & A1967C & D656A \\
\hline & & $y d h K$ & C305A & A102E \\
\hline$\# 24$ & 2 & pta & $\mathrm{T} 2 \mathrm{~A}^{* 2}$ & No initiation \\
\hline$\# 25$ & 2 & pta & A1967C & D656A \\
\hline$\# 27$ & 2 & pta & A1967C & D656A \\
\hline \#29 & 2 & pta & A1967C & D656A \\
\hline \#31-1 & 3 & $l p d$ & C963A & H322Q \\
\hline \multirow[t]{2}{*}{ \#32-1 } & 3 & aceE & G1193T & G398V \\
\hline & & yhix & $\mathrm{C} 831 \mathrm{~T} * 3$ & Silent \\
\hline \#33-1 & 3 & entE & C827T & T276I \\
\hline \#35-1 & 3 & pta & A1967C & D656A \\
\hline \#37-1 & 3 & aceF & C1700A & A567E \\
\hline \multirow[t]{2}{*}{ \#39-2 } & 3 & aceE & C617T & A206V \\
\hline & & aceE & G810A *3 & silent \\
\hline$\# 40-2$ & 3 & pta & C1884G & D628E \\
\hline \#43-1 & 3 & lpd & T956G & L320R \\
\hline \#44-1 & 3 & cyaA & C1957T & R653C \\
\hline$\# 45-1$ & 3 & pta & A1967C & D656A \\
\hline$\# 46-2$ & 3 & pta & A1967C & D656A \\
\hline \multirow[t]{2}{*}{ \#48-1 } & 3 & aceE & G440A & G147D \\
\hline & & flhC & C115 deletion $* 4$ & 39 frameshift \\
\hline \#51 & 3 & $y n b B$ & A380C & D127A \\
\hline \multirow{2}{*}{ \#54 } & 3 & aceE & T584C & M195T \\
\hline & & $f t s I$ & $\mathrm{C} 1599 \mathrm{~T}^{* 3}$ & Silent \\
\hline \#57 & 3 & $l p d$ & T956G & L320R \\
\hline \#64-1 & 4 & cyaA & $\mathrm{C} 1957 \mathrm{~T}$ & $\mathrm{R} 653 \mathrm{C}$ \\
\hline$\# 65-2$ & 4 & yhjG & $\mathrm{T} 543 \mathrm{~A}$ & D181E \\
\hline \multirow[t]{2}{*}{ \#68-1 } & 4 & cyaA & C1957T & $\mathrm{R} 653 \mathrm{C}$ \\
\hline & & $g \ln S$ & A956T & Q319L \\
\hline$\# 70$ & 4 & ack $A$ & A878 deletion $* 4$ & 293 frameshift \\
\hline
\end{tabular}

Amino acid residues are represented using the one-letter code. ${ }^{* 1}$ Adenine is inserted after $123 \mathrm{~A}$, causing a frameshift mutation at amino acid residue 42. ${ }^{* 2}$ T2A mutation disrupts the initiation codon. ${ }^{* 3}$ Nucleotide changes in suppressor mutants \#32-1, \#39-2, and \#54 generate silent mutations. ${ }^{* 4}$ Deletion of a nucleotide in suppressor mutants \#48-1 and \#70 causes a frameshift mutation at amino acid residues 39 and 293, respectively. 
Intriguingly, 17 clones carried a point mutation in pta and one clone in $a c k A$; both genes are part of an acetate-synthesizing pathway, the PTA-ACKA pathway (Table 3 and Table S3). Moreover, 11, two, and three clones carried point mutations in aceE, aceF, and $l p d$, respectively, which encode subunits of the multi-component enzyme PDH. Overall, $34 / 40$ clones of L-alanine suppressors (85\%) harbored mutations in metabolic pathways downstream from pyruvate that enters the TCA cycle and the PTA-ACKA pathway (Table 3 and Table S3).

\subsection{Characterization of Mutations Identified in pta and aceE}

We hypothesized that the individual mutations identified here represent a major cause of the appearance of L-alanine suppressors. To verify this, we selected two suppressor mutants as model systems: \#8-2, carrying a point mutation (pta, D656A) found in 14 independent clones; and \#13-1, carrying a point mutation (aceE, G147D) found in two independent clones. We singly introduced the point mutations D656A and G147D into the parent L-alanine auxotroph HYE032 through homologous recombination to obtain clones \#8-2M and \#13-1M, respectively. The generated isogenic mutants showed growth recovery in minimal medium to a level similar to that observed in their original suppressor mutants, \#8-2 and \#13-1, respectively (Figure 4), which indicated clearly that the individual point mutations caused the suppression phenotype of the mutant clones.
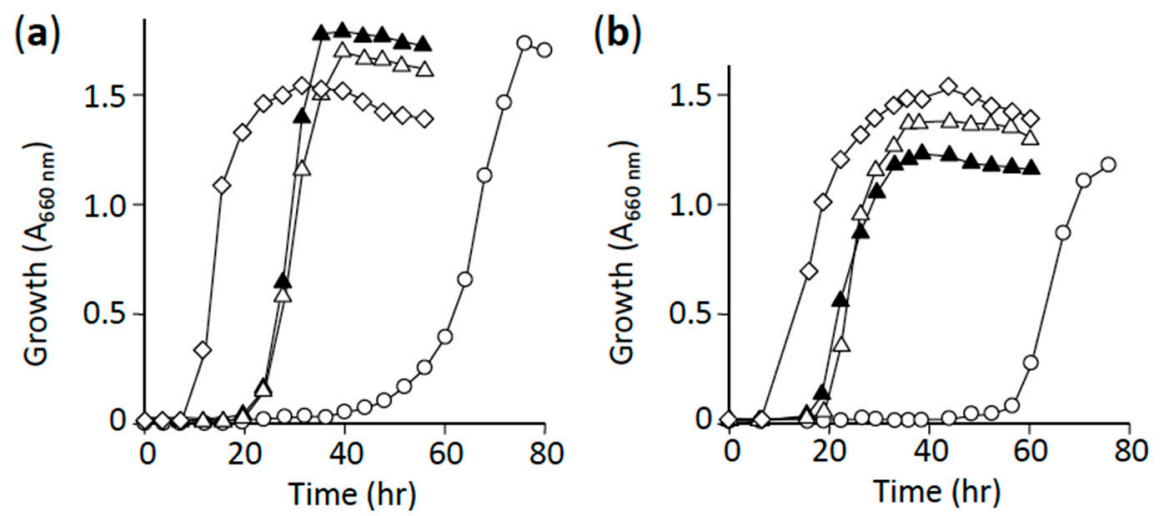

Figure 4. Growth of L-alanine prototrophic suppressor mutants and their cognate isogenic mutants in liquid minimal medium. (a) Clone \#8-2 and its isogenic mutant \#8-2M. (b) Clone \#13-1 and its isogenic mutant \#13-1M. Symbols: open diamonds, W3110; open circles, HYE032; open triangles, original L-alanine suppressors \#8-2 (a) and \#13-1 (b); closed triangles, respective isogenic mutants $\# 8-2 \mathrm{M}(\mathbf{a})$ and \#13-1M (b). The figure shows representative results from 3 independent experiments.

Next, we determined the enzyme activities of PTA and PDH in the suppressor mutants and their isogenic mutants to assess the biochemical background for the suppression phenotype. As expected, the pta suppressor (\#8-2) and its isogenic mutant (\#8-2M) derived from the L-alanine auxotroph showed negligible PTA activity (Figure 5). Similarly, the aceE suppressor (\#13-1) and its isogenic mutant (\#13-1M) showed extremely low PDH activity as compared with their parental strain (HYE032) and the wild-type strain (W3110) (Figure 5). These results implied that the metabolic flow at each of these enzymatic reaction steps could be restricted, which would result in pyruvate accumulation in cells; this change in metabolic flow, in turn, could produce a shift toward L-alanine generation due to increased levels of pyruvate, the immediate precursor of L-alanine. Both enzyme activities in the L-alanine auxotroph HYE032 were comparable to those in its parental strain (W3110), which indicated that blockage of L-alanine formation itself did not influence PTA and PDH activities. 
(a)

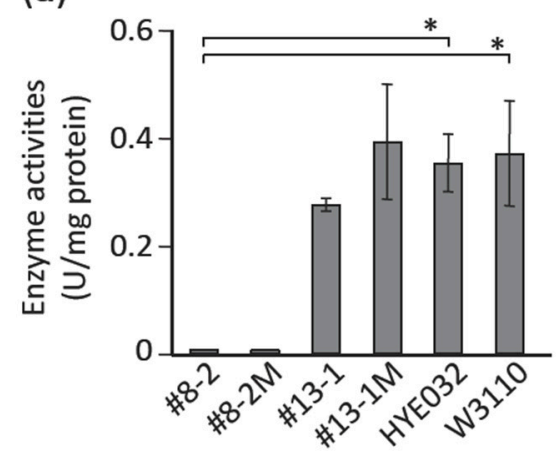

(b)

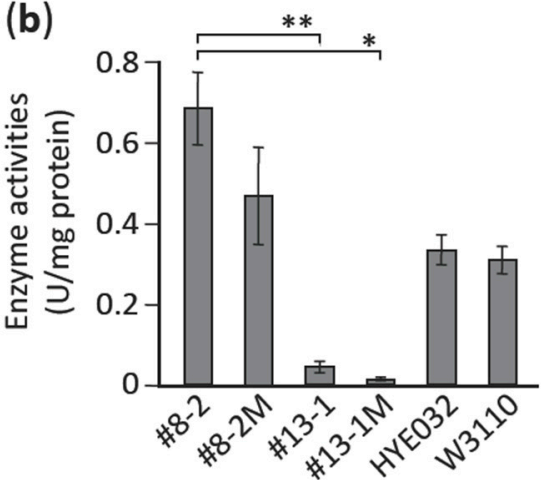

Figure 5. Enzyme activities of pyruvate transacetylase (a) and pyruvate dehydrogenase (b) in L-alanine suppressors \#8-2 and \#13-1 and their cognate isogenic mutants \#8-2M and \#13-1M. Data represent means and standard deviation of 3 independent experiments. Statistical analyses in (a) ${ }^{*} p<0.05$ and $(\mathbf{b}) * p<0.01,{ }^{* *} p<0.001$.

\subsection{Impact of Extracellular Pyruvate and Anaerobic Culture Conditions on Emergence of L-Alanine Prototrophic Suppressors}

The results in the preceding subsection indicated that the mutations that led to an increase in intracellular pyruvate levels represented the underlying mutations in the L-alanine prototrophic suppressors, and that a metabolic stress-here, L-alanine starvation-induced the suppressor mutations. Thus, we hypothesized that changes in intracellular levels of pyruvate could, conversely, affect the appearance of L-alanine prototrophic suppressors, and to test this, we determined the emergence frequency of L-alanine prototrophic suppressor mutants after culturing HYE032 cells in minimal liquid medium supplemented with pyruvate (Figure 6): L-alanine prototrophic suppressors appeared in the population of late-log-phase cells with decreasing frequency as the amount of extracellularly added pyruvate was increased. Because intracellular levels of pyruvate are related to extracellular pyruvate concentrations [25], the result implied that L-alanine starvation stress is relieved by pyruvate supplementation in the medium, which leads to low frequencies of appearance of L-alanine prototrophic suppressors.

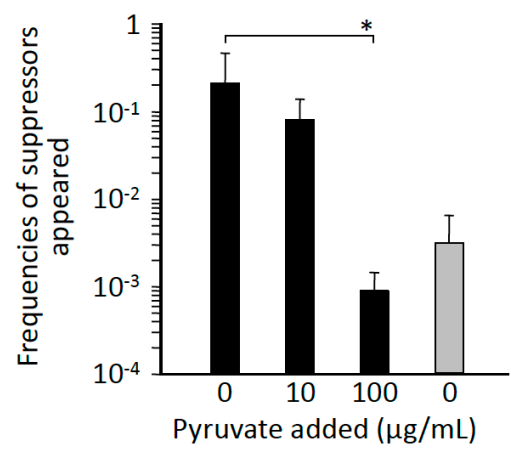

Figure 6. Effects of culture conditions on appearance of L-alanine prototrophic suppressors in minimal medium. HYE032 cells were inoculated into the minimal liquid medium and grown aerobically (black bars) in the presence of pyruvate $(10$ and $100 \mu \mathrm{g} / \mathrm{mL})$ or grown anaerobically to the late-log phase (grey bar). Subsequently, the frequency of appearance of suppressors was measured. Data represent means and standard deviation from 3 independent experiments. Statistical analyses; ${ }^{*} p<0.05$.

To further substantiate our finding, we determined the emergence frequencies of L-alanine suppressor mutants after culturing HYE032 cells anaerobically, a condition widely recognized to increase metabolic flow through the glycolysis pathway leading to pyruvate generation [26,27]. As per our expectation, the frequencies of L-alanine prototrophic suppressor mutants were markedly decreased as compared to those observed under aerobic culture conditions with no L-alanine supplementation (Figure 6), which 
clearly indicated that the L-alanine starvation stress exerted on the L-alanine auxotroph HYE032 was relieved by intrinsically synthesized pyruvate.

\section{Discussion}

In this study, we found that L-alanine prototrophic suppressor mutants emerged due to mutagenesis induced by stress (in this case, L-alanine starvation); our conclusion here is based on the following results: (1) L-alanine prototrophic mutants appeared under nonlethal selection conditions in a time-dependent manner (Figure 1a); (2) the frequencies of appearance of the suppressor mutants were higher than that due to spontaneous mutation, which agrees well with other nonlethal selection systems involving the use of lactose and amino acid auxotrophs [28-30]; and (3) the frequencies of L-alanine prototrophic suppressors in the late-log-phase population were inversely related to the L-alanine levels present in minimal liquid medium (Figure 1b).

We propose that the suppressor mutants are generated through the following steps: (1) perception of the environmental stress (L-alanine starvation), (2) activation of an intracellular signaling cascade that currently remains unelucidated, (3) involvement of the nucleic acid metabolic process that leads to a mutation(s), and (4) L-alanine biosynthesis that supports the growth of the L-alanine auxotroph HYE032 in the absence of L-alanine supplementation (Figure 7). Regarding Step 4, the three genes encoding the isozymes AvtA, YfbQ, and YfdZ, which synthesize L-alanine, were knocked out using a gene-replacement technique, and thus reversion of each respective L-alanine-generating gene product theoretically cannot occur. Accordingly, the L-alanine prototrophic suppressor mutants could harbor mutations in a gene(s) other than $a v t A, y f b Q$, and $y f d Z$. The results of whole-genome sequencing analysis of the obtained suppressors confirmed this view (Table 3 and Table S3).

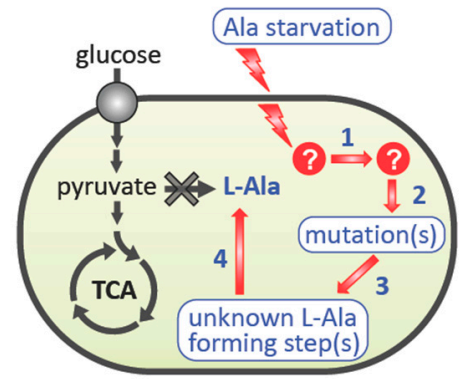

Figure 7. Model depicting stress-induced mutagenesis leading to the emergence of L-alanine prototrophic suppressor mutants. The L-alanine auxotrophic strain HYE032 senses the stress of L-alanine starvation, which leads to activation of a DNA-related metabolic pathway (Step 1). Subsequently, a genome-wide mutation(s) is introduced (Step 2) in a subpopulation of the cells. Some of the clones obtain, by chance, the ability to increase their intracellular level of pyruvate (Step 3), which provides HYE032 cells with an adequate amount of L-alanine to proliferate (Step 4).

The most physiologically relevant result presented here is that 18 and 16 suppressor mutants were found to carry mutations in genes that function in the metabolic steps immediately downstream of pyruvate, in the PTA-ACKA pathway and PDH complex, respectively (Table 3 and Table S3). This result agrees well with that of an earlier study in which multicopy suppression in an L-alanine auxotroph was observed with serC [6], the gene encoding the enzyme 3-phosphoserine aminotransferase involved in L-serine biosynthesis; this finding implies that pyruvate could be a minor substrate of SerC in the generation of L-alanine [6]. Accordingly, a mutation(s) that leads to an increase in the intracellular level of pyruvate is highly likely to occur in a suppressor mutant that carries a single copy of wild-type $\operatorname{ser} C$ in the genome. This scenario is verified by the findings that (1) isogenic mutants derived from the L-alanine auxotroph HYE032 harboring the pta mutation (clone \#8-2) or aceE mutation (clone \#13-1) show L-alanine prototrophy (Figure 4), and (2) both isogenic mutants exhibit markedly low activity of the respective enzymes (Figure 5). The aforementioned results agree closely with the results of previous 
metabolic engineering studies, in which genetic manipulation leading to elimination or downregulation of PDH activity and/or the acetate metabolic pathway ( $p t a$ and ackA) promoted pyruvate production [31-33].

In addition to the mutation-carrying genes of the PDH complex (aceE, aceF, and lpd) and the PTA-ACKA pathway (pta and $a c k A$ ), 14 genes were found to harbor a point mutation in the L-alanine prototrophic suppressors (Table 3 and Table S3). Notably, among these mutations, the same mutation in cyaA (C1957T, which produces the R653C amino acid change in the encoded adenylate cyclase) was found in four suppressor mutants: \#10-1, \#44-1, \#64-1, and \#68-1; the mutants \#44-1 and \#64-1 carried only the cyaA mutation, whereas \#10-1 and \#68-1 harbored an additional mutation, in aceE and $g \ln S$, respectively. By contrast, the remaining 13 suppressor mutations did not appear in more than one mutant. Currently, we cannot explain clearly how these mutations contribute to the L-alanine prototrophy in each suppressor mutant (\#33-1, \#44-1, \#51, \#64-1, \#65-2, and \#68-1) that did not also concurrently possess a mutation in $\mathrm{pta}$ or aceE. Intriguingly, however, among these mutants, three mutants (\#64-1, \#68-1, and \#44-1) possess the aforementioned cyaA point mutation (C1957T). This mutation is expected to lower adenylate cyclase activity and thereby lead to reduced levels of the intracellular messenger cAMP, which, in turn, could regulate an as yet unknown pathway(s) and cause the accumulation of intracellular pyruvate. This possibility is in accord with the notion that the ratio [phosphoenolpyruvate]/[pyruvate] is positively correlated with the phosphorylation level of the phosphotransferase system component enzyme IIAGlc [34], and that the phosphorylated enzyme IIAGlc activates adenylate cyclase, which results in the production of cAMP [35].

To obtain more insight into the aforementioned complicated metabolic network, we must perform more in-depth experiments, such as the construction of the isogenic mutant harboring the cyaA point mutation (C1957T). In addition, we should address the important question of how L-alanine starvation stress induces mutation(s) by isolating mutants that do not show high-frequency of the emergence of L-alanine prototrophic suppressor mutants.

The most notable feature of the results obtained in this study is that the L-alanine prototrophic suppressors were generated by stress-induced mutagenesis. Bacteria constantly face environmental changes, which could be harmful under a given condition but also nonlethal under another. Bacteria respond to these stresses through mutation, where a cell that obtains a beneficial mutation survives to generate a mutant strain under the stress conditions. Mutants have long been recognized to arise through spontaneous mutation, which occurs without the influence of selective stress, as revealed by the elegant experiments of Luria and Delbruck [36] and Lederberg and Lederberg [37]. However, this concept has been challenged by the 1988 Cairns study of adaptive mutagenesis [38], which posits that mutations emerge after cells encounter a growth-limiting environment (i.e., a stress) instead of occurring independently of the stress. To explain this phenomenon, the hypermutable state model has been proposed, in which a cell subpopulation enters a transient hypermutation state that provokes a high mutation rate under stress conditions [39,40], and this process has further been shown to generate genome-wide mutation in the subpopulation [41]. This model could explain the occurrence of the L-alanine prototrophic suppressors obtained in this study, because genome sequencing of the independent suppressor mutants revealed that 14 genes, besides the genes related to the PDH complex and PTA-ACKA pathway, carried a mutation as described above, and more importantly, eight and one suppressor clones respectively harbored two and three distinct point mutations in different genes concurrently (Table 3 and Table S3). Therefore, the emergence of L-alanine prototrophic suppressor mutants derived from the L-alanine auxotroph represents a favorable experimental system for a comprehensive investigation of stress-induced mutagenesis. Moreover, this study provides, to the best of our knowledge, the first example indicating that stressinduced mutagenesis can be used to select for a high-producer strain of a metabolite in the bioengineering process. 
Supplementary Materials: The following are available online at https:/ /www.mdpi.com/2076-260 7/9/3/472/s1, Figure S1: Emergence of L-alanine prototrophic mutants from L-alanine auxotroph HYE032; Figure S2: Growth of L-alanine prototrophic suppressor mutants obtained on minimal agar medium; Figure S3: Effect of L-glutamic acid on the growth of L-alanine auxotroph HYE032; Table S1: Primers used for sequencing of candidate genes; Table S2: Summary of suppressor mutants in terms of numbers of genes harboring mutation(s); Table S3: Summary of suppressor mutants in terms of genes mutated.

Author Contributions: Conceptualization, H.Y.; genome sequencing analysis, T.K.; static analysis, T.N.; investigation, H.M., H.W., K.U., S.S. (So Shimoda), S.S. (Shota Seki), T.A., and H.Y.; writingoriginal draft preparation, H.M.; writing—-review and editing, H.Y.; project administration, H.Y.; funding acquisition, H.Y. All authors have read and agreed to the published version of the manuscript.

Funding: This research was funded in part by the Grant-in-Aid for Challenging Exploratory Research from the Japan Society for the Promotion of Science, JSPS KAKENHI grant number JP24658067 and, in part, by the Core-to-Core Program (Advanced Research Networks) of the Japan Society for the Promotion of Science.

Institutional Review Board Statement: Not applicable.

Informed Consent Statement: Not applicable.

Acknowledgments: We thank Emiko Isogai and Hideaki Maseda for their valuable discussions.

Conflicts of Interest: The authors declare no conflict of interest. The funders had no role in the design of the study; in the collection, analyses, or interpretation of data; in the writing of the manuscript, or in the decision to publish the results.

\section{References}

1. Reed, J.L.; Vo, T.D.; Schilling, C.H.; Palsson, B.O. An expanded genome-scale model of Escherichia coli K-12 (iJR904 GSM/GPR). Genome Biol. 2003, 4, R54. [CrossRef]

2. Umbarger, H.E. Amino Acid Biosynthesis and its Regulation. Annu. Rev. Biochem. 1978, 47, 533-606. [CrossRef] [PubMed]

3. Reitzer, L.J. Ammonia Assimilation and the Biosynthesis of Glutamine, Glutamate, Aspartate, Asparagine, L-Alanine, and D-Alanine. In Escherichia Coli and Salmonella: Cellular and Molecular Biology; Frederick, C.N., John, L.I., Boris, M., Brooks, K.L., Moselio, S., Edwin, U.H., Eds.; ASM Press: Washington, DC, USA, 1996; pp. 391-407.

4. Pittard, A.J. Biosynthesis of the Aromatic Amino Acids. In Escherichia Coli and Salmonella: Cellular and Molecular Biology; Frederick, C.N., John, L.I., Boris, M., Brooks, K.L., Moselio, S., Edwin, U.H., Eds.; ASM Press: Washington, DC, USA, 1996 ; pp. 458-484.

5. Patte, J.-C. Biosynthesis of Threonine and Lysine. In Escherichia Coli and Salmonella: Cellular and Molecular Biology; Frederick, C.N., John, L.I., Boris, M., Brooks, K.L., Moselio, S., Edwin, U.H., Eds.; ASM Press: Washington, DC, USA, 1996.

6. Yoneyama, H.; Hori, H.; Lim, S.-J.; Murata, T.; Ando, T.; Isogai, E.; Katsumata, R. Isolation of a Mutant Auxotrophic for L-Alanine and Identification of Three Major Aminotransferases That SynthesizeL-Alanine in Escherichia coli. Biosci. Biotechnol. Biochem. 2011, 75, 930-938. [CrossRef]

7. Kim, S.H.; Schneider, B.L.; Reitzer, L. Genetics and Regulation of the Major Enzymes of Alanine Synthesis in Escherichia coli. J. Bacteriol. 2010, 192, 5304-5311. [CrossRef] [PubMed]

8. Patrick, W.M.; Quandt, E.M.; Swartzlander, D.B.; Matsumura, I. Multicopy Suppression Underpins Metabolic Evolvability. Mol. Biol. Evol. 2007, 24, 2716-2722. [CrossRef]

9. Notebaart, A.R.; Kintses, B.; Feist, A.M.; Papp, B. Underground metabolism: Network-level perspective and biotechnological potential. Curr. Opin. Biotechnol. 2018, 49, 108-114. [CrossRef]

10. Cocks, G.T.; Aguilar, J.; Lin, E.C.C. Evolution of L-1, 2-propanediol catabolism in Escherichia coli by recruitment of enzymes for L-fucose and L-lactate metabolism. J. Bacteriol. 1974, 118, 83-88. [CrossRef] [PubMed]

11. Martin, E.J.S.; Mortlock, R.P. Natural and altered induction of the L-fucose catabolic enzymes in Klebsiella aerogenes. J. Bacteriol. 1976, 127, 91-97. [CrossRef] [PubMed]

12. Hall, B.G. The EBG system of E. coli: Origin and evolution of a novel beta-galactosidase for the metabolism of lactose. Genetica 2003, 118, 143-156. [CrossRef]

13. Kang, L.; Shaw, A.C.; Xu, D.; Xia, W.; Zhang, J.; Deng, J.; Woldike, H.F.; Liu, Y.; Su, J. Upregulation of MetC is essential for D-alanine-independent growth of an alr/dadX-deficient Escherichia coli strain. J. Bacteriol. 2011, 193, 1098-1106. [CrossRef] [PubMed]

14. Fisher, R.; Tuli, R.; Haselkorn, R. A cloned cyanobacterial gene for glutamine synthetase functions in Escherichia coli, but the enzyme is not adenylylated. Proc. Natl. Acad. Sci. USA 1981, 78, 3393-3397. [CrossRef]

15. Hashimoto-Gotoh, T.; Yamaguchi, M.; Yasojima, K.; Tsujimura, A.; Wakabayashi, Y.; Watanabe, Y. A set of temperature sensitivereplication/-segregation and temperature resistant plasmid vectors with different copy numbers and in an isogenic background (chloramphenicol, kanamycin, lacZ, repA, par, polA). Gene 2000, 241, 185-191. [CrossRef] 
16. Hori, H.; Yoneyama, H.; Tobe, R.; Ando, T.; Isogai, E.; Katsumata, R. Inducible L-alanine exporter encoded by the novel gene ygaW (alaE) in Escherichia coli. Appl. Environ. Microbiol. 2011, 77, 4027-4034. [CrossRef] [PubMed]

17. Langmead, B.; Salzberg, S.L. Fast gapped-read alignment with Bowtie 2. Nat. Methods 2012, 9, 357-359. [CrossRef] [PubMed]

18. Li, H.; Handsaker, B.; Wysoker, A.; Fennell, T.; Ruan, J.; Homer, N.; Marth, G.; Abecasis, G.; Durbin, R.; 1000 Genome Project Data Processing Subgroup. The Sequence Alignment/Map format and SAMtools. Bioinformatics 2009, 25, 2078-2079. [CrossRef]

19. Garrison, E.; Marth, G. Haplotype-based variant detection from short-read sequencing. arXiv 2012, arXiv:1207.3907.

20. Danecek, P.; Auton, A.; Abecasis, G.; Albers, C.A.; Banks, E.; Depristo, M.A.; Handsaker, R.E.; Lunter, G.; Marth, G.T.; Sherry, S.T.; et al. The variant call format and VCFtools. Bioinformatics 2011, 27, 2156-2158. [CrossRef]

21. Sanger, F.; Nicklen, S.; Coulson, A.R. DNA sequencing with chain-terminating inhibitors. Proc. Natl. Acad. Sci. USA 1977, 74, 5463-5467. [CrossRef] [PubMed]

22. Hinman, L.M.; Blass, J.P. An NADH-linked spectrophotometric assay for pyruvate dehydrogenase complex in crude tissue homogenates. J. Biol. Chem. 1981, 256, 6583-6586. [CrossRef]

23. Ferry, J.G. Acetate Kinase and Phosphotransacetylase. Methods Enzymol. 2011, 494, 219-231. [CrossRef] [PubMed]

24. Lowry, O.H.; Rosebrough, N.J.; Farr, A.L.; Randall, R.J. Protein measurement with the Folin phenol reagent. J. Biol. Chem. 1951, 193, 265-275. [CrossRef]

25. Yanga, Y.-T.; Bennett, G.N.; San, K.-Y. The Effects of Feed and Intracellular Pyruvate Levels on the Redistribution of Metabolic Fluxes in Escherichia coli. Metab. Eng. 2001, 3, 115-123. [CrossRef]

26. Wang, Q.; Ou, M.S.; Kim, Y.; Ingram, L.O.; Shanmugam, K.T. Metabolic Flux Control at the Pyruvate Node in an Anaerobic Escherichia coli Strain with an Active Pyruvate Dehydrogenase. Appl. Environ. Microbiol. 2010, 76, 2107-2114. [CrossRef]

27. Chen, X.; Alonso, A.P.; Allen, D.K.; Reed, J.L.; Shachar-Hill, Y. Synergy between 13C-metabolic flux analysis and flux balance analysis for understanding metabolic adaption to anaerobiosis in E. coli. Metab. Eng. 2011, 13, 38-48. [CrossRef]

28. Cairns, J.; Foster, P.L. Adaptive reversion of a frameshift mutation in Escherichia coli. Genetics 1991, 128, 695-701. [CrossRef]

29. Bridges, B.A. Starvation-associated mutation in Escherichia coli: A spontaneous lesion hypothesis for "directed" mutation. Mutat. Res. Mol. Mech. Mutagen. 1994, 307, 149-156. [CrossRef]

30. Godoy, V.G.; Gizatullin, F.S.; Fox, M.S. Some features of the mutability of bacteria during nonlethal selection. Genetics 2000, 154, 49-59.

31. Yokota, A.; Shimizu, H.; Terasawa, Y.; Takaoka, N.; Tomita, F. Pyruvic acid production by a lipoic acid auxotroph of Escherichia coliW1485. Appl. Microbiol. Biotechnol. 1994, 41, 638-643. [CrossRef]

32. Wu, J.; Li, Y.; Cai, Z.; Jin, Y. Pyruvate-Associated Acid Resistance in Bacteria. Appl. Environ. Microbiol. 2014, 80, 4108-4113. [CrossRef] [PubMed]

33. Tomar, A.; Eiteman, M.A.; Altman, E. The effect of acetate pathway mutations on the production of pyruvate in Escherichia coli. Appl. Microbiol. Biotechnol. 2003, 62, 76-82. [CrossRef] [PubMed]

34. Cunningham, D.S.; Liu, Z.; Domagalski, N.; Koepsel, R.R.; Ataai, M.M.; Domach, M.M. Pyruvate Kinase-Deficient Escherichia coli Exhibits Increased Plasmid Copy Number and Cyclic AMP Levels. J. Bacteriol. 2009, 191, 3041-3049. [CrossRef] [PubMed]

35. Hogema, B.M.; Arents, J.C.; Bader, R.; Eijkemans, K.; Yoshida, H.; Takahashi, H.; Aiba, H.; Postma, P.W. Inducer exclusion in Escherichia coli by non-PTS substrates: The role of the PEP to pyruvate ratio in de-termining the phosphorylation state of enzyme IIAGlc. Mol. Microbiol. 1998, 30, 487-498. [CrossRef]

36. Luria, S.E.; Delbruck, M. Mutations of Bacteria from Virus Sensitivity to Virus Resistance. Genetics 1943, 28, 491-511. [PubMed]

37. Lederberg, J.; Lederberg, E.M. Replica Plating and Indirect Selection of Bacterial Mutants. J. Bacteriol. 1952, 63, 399-406. [CrossRef] [PubMed]

38. Cairns, J.; Overbaugh, J.; Miller, S. The origin of mutants. Nat. Cell Biol. 1988, 335, 142-145. [CrossRef]

39. Hall, B.G. Spontaneous point mutations that occur more often when advantageous than when neutral. Genetics 1990, 126, 5-16. [CrossRef] [PubMed]

40. Rosche, W.A.; Foster, P.L. The role of transient hypermutators in adaptive mutation in Escherichia coli. Proc. Natl. Acad. Sci. USA 1999, 96, 6862-6867. [CrossRef] [PubMed]

41. Torkelson, J.; Harris, R.S.; Lombardo, M.J.; Nagendran, J.; Thulin, C.; Rosenberg, S.M. Genome-wide hypermutation in a subpopulation of stationary-phase cells underlies recombina-tion-dependent adaptive mutation. EMBO J. 1997, 16, 3303-3311. [CrossRef] [PubMed] 